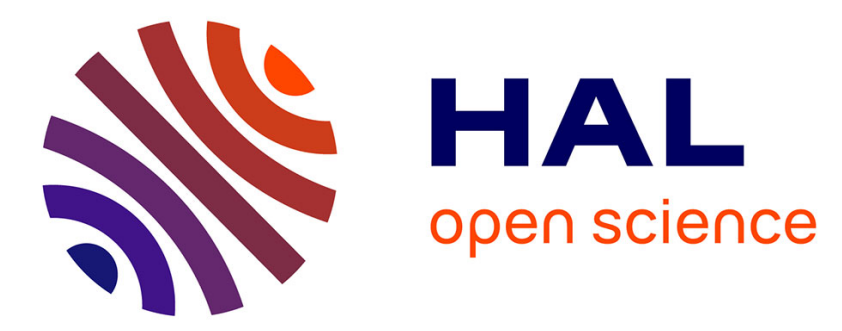

\title{
Combination of two catalytic sites in a novel nanocrystalline TiO2-iron tetrasulfophthalocyanine material provides better catalytic properties
} Mirvat Beyrhouty, A.B. Sorokin, S. Daniele, L.G. Hubert-Pfalzgraf

\section{To cite this version:}

Mirvat Beyrhouty, A.B. Sorokin, S. Daniele, L.G. Hubert-Pfalzgraf. Combination of two catalytic sites in a novel nanocrystalline $\mathrm{TiO} 2$-iron tetrasulfophthalocyanine material provides better catalytic properties. New Journal of Chemistry, 2005, 29 (10), pp.1245-1248. hal-00009413

\section{HAL Id: hal-00009413 \\ https://hal.science/hal-00009413}

Submitted on 3 Oct 2005

HAL is a multi-disciplinary open access archive for the deposit and dissemination of scientific research documents, whether they are published or not. The documents may come from teaching and research institutions in France or abroad, or from public or private research centers.
L'archive ouverte pluridisciplinaire HAL, est destinée au dépôt et à la diffusion de documents scientifiques de niveau recherche, publiés ou non, émanant des établissements d'enseignement et de recherche français ou étrangers, des laboratoires publics ou privés. 


\title{
Combination of two catalytic sites in a novel nanocrystalline $\mathrm{TiO}_{2}$-iron tetrasulfophthalocyanine material provides better catalytic properties
}

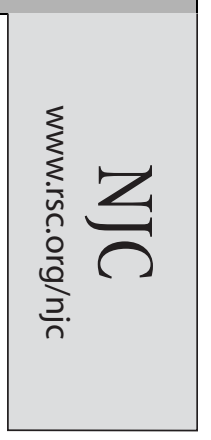

\author{
Mirvat Beyrhouty, Alexander B. Sorokin,* Stéphane Daniele* and \\ Liliane G. Hubert-Pfalzgraf
}

Institut de Recherches sur la Catalyse, UPR 5401, Université Claude Bernard Lyon 1,

2 avenue A. Einstein, 69626 Villeurbanne Cedex, France.E-mail: daniele@catalyse.cnrs.fr

Received (in Montpellier, France) 23rd May 2005, Accepted 7th July 2005

First published as an Advance Article on the web 8th August 2005

\begin{abstract}
Mesoporous titania nanocrystals containing iron tetrasulfophthalocyanine (FePcS) have been synthesised by a one-pot hydrolytic process from a modified Ti alkoxide; the novel hybrid catalyst was efficient in heterogeneous oxidation of 2,3,6-trimethylphenol and $\beta$-isophorone suggesting a cooperative effect between $\mathrm{TiO}_{2}$ and $\mathrm{FePcS}$ catalytic sites.
\end{abstract}

Nano-sized functional hybrid materials have become a highly innovative research field. The ability to tailor the organic part combined with the properties of the nano-sized inorganic matrixes is of great interest for potential applications in electronics, optics and catalysis. In particular, an association of a metal complex with a catalytically active inorganic support could provide a catalyst having improved catalytic properties due to the combination of two different catalytic sites in one material.

Recently we reported the synthesis of nanocrystalline particles of titania at low temperature $\left(100{ }^{\circ} \mathrm{C}\right)$ by a sol-gel process using titanium alkoxide and bromide ammonium salts as catalysts. ${ }^{1}$ This synthetic approach could allow to introduce acid-containing compounds into $\mathrm{TiO}_{2}$ particles via the synthesis of hybrid nanoparticles from modified titanium alkoxides. Taking into account the catalytic properties of FePcS in the selective oxidation of alkynes ${ }^{2}$ and aromatic compounds ${ }^{3}$ as well as in the oxidative degradation of organic pollutants ${ }^{4}$ this complex containing four sulfonic groups seemed to be a suitable candidate. Photocatalytic degradation studies of pollutants using either $\mathrm{Co}$ (II)-tetrasulfophthalocyanine grafted on $\mathrm{TiO}_{2}$ via a silane reagent ${ }^{5}$ or polycrystalline $\mathrm{TiO}_{2}$ samples impregnated with $\mathrm{Cu}(\mathrm{II})$-phthalocyanine ${ }^{6}$ were reported in the literature. However, to the best of our knowledge, none stemmed from direct covalent bonding of functionalized phthalocyanine on nanoparticulate $\mathrm{TiO}_{2}$ material. In this work, we report a practical one-pot sol-gel preparation of surface-modified nanocrystalline titania particles from heteroleptic alkoxide and their catalytic activities in the aerobic oxidation of $\beta$-isophorone.

Iron(III) tetrasulfophthalocyanine chloride $\left[\mathrm{FePc}\left(\mathrm{SO}_{3} \mathrm{H}\right)_{4}\right] \mathrm{Cl}$ was used to substitute alkoxide ligands (Fig. 1). The reaction between $\left[\mathrm{FePc}\left(\mathrm{SO}_{3} \mathrm{H}\right)_{4}\right] \mathrm{Cl}$ and excess of $\mathrm{Ti}\left(\mathrm{OPr}^{\mathrm{i}}\right)_{4}$ in refluxing 2-propanol for $12 \mathrm{~h}$ resulted in a blue-green crystalline material 1 (yield $=60 \%$ based on $\left.\left[\mathrm{FePc}\left(\mathrm{SO}_{3} \mathrm{H}\right)_{4}\right] \mathrm{Cl}\right)$. Elemental analysis gave a ratio $\mathrm{Ti} / \mathrm{Fe}=40$. UV-Vis and FT-IR spectra indicated that the structure of phthalocyanine is retained upon modification. 1 was hydrolysed in pure water in the presence of tetrabutylammonium bromide salt to give material $\mathbf{2}$ which was characterised by elemental analysis, FT-IR, XRD, TEM, BET, UV-Visible and XPS techniques.
The FT-IR analyses of $\mathbf{2}$ showed the absorption peaks related to $\nu \mathrm{OH}$ and new $\nu \mathrm{SO}_{3}$ stretching vibrations between 1260 and $1000 \mathrm{~cm}^{-1}$ (in comparison to $\left[\mathrm{FePc}\left(\mathrm{SO}_{3} \mathrm{H}\right)_{4}\right] \mathrm{Cl}$ ). This reveals that sulfonic acid groups are chemisorbed as sulfonates onto the $\mathrm{TiO}_{2}$ nanoparticles. XPS spectra recorded from 0 to $1200 \mathrm{eV}$ indicated that the hybrid material contained iron $[\mathrm{Fe} 2 \mathrm{p} 3 / 2=709.1 \mathrm{eV}]$, titanium [Ti2p 3/2 $=458.8 \mathrm{eV}]$, nitrogen $[\mathrm{N} 1 \mathrm{~s}=400.3(50 \%), 398.8(50 \%) \mathrm{eV}]$, sulfur $[\mathrm{S} 2 \mathrm{p}=167,3 \mathrm{eV}]$, oxygen $[\mathrm{O} 1 \mathrm{~s}=532.1(18 \%), 530.2(82 \%) \mathrm{eV}]$, carbon $[\mathrm{C} 1 \mathrm{~s}=$ $284.6 \mathrm{eV}]$ and an atomic ratio $\mathrm{Ti} 2 \mathrm{p} / \mathrm{Fe} 2 \mathrm{p}=23$. The two O1s peaks at 532.1 and $530.2 \mathrm{eV}$ are ascribed to the $\mathrm{O}^{2-}$ contributions of sulfonate and oxide ligands, respectively. The binding energy values of the O1s and S2p peaks of the sulfonate groups are different in comparison to the free ligand $[\mathrm{O} 1 \mathrm{~s}=531.1 \mathrm{eV}$, $\mathrm{S} 2 \mathrm{p}=168,1 \mathrm{eV}$, suggesting $\mathrm{SO}_{3}$ covalent bonding onto $\mathrm{TiO}_{2}$. According to the assignment made by Gosh et al. ${ }^{7}$ based on all-electron ab initio HF calculations on the metal-free phthalocyanine, the N1s peak at $400.3 \mathrm{eV}$ is assigned to the four pyrrolic nitrogens (the inner ones bonded with two carbons and the central $\mathrm{Fe}$ atom). The absence of a chlorine peak indicates that under sol-gel conditions it was replaced by hydroxo or oxo ligands. Diffuse reflectance UV-Vis spectroscopy of $\mathbf{2}$ confirmed the presence of intact tetrasulfophthalocyanine. The intense Q-band at $641 \mathrm{~nm}$ suggests that phthalocyanine exits predominantly in dimeric form while the shoulder at $696 \mathrm{~nm}$ could be attributed to the monomer form. Such dimerisation has already been observed for aluminium tetrasulfophthalocyanine chloride in sol-gel processing. ${ }^{8}$ The loading of the hybrid material $\left(214 \mu \mathrm{mol} \mathrm{g}^{-1}\right.$ or $19.2 \mathrm{wt} \%$ of phthalocyanine), determined by ICP-MS on iron, is high and could be easily modulated by adding various equivalents of $\operatorname{Ti}\left(\mathrm{OPr}^{\mathrm{i}}\right)_{4}$ during the hydrolysis. XRD patterns, obtained at the scan rate of $0.02^{\circ} 2 \theta \mathrm{s}^{-1}$, show that 2 contains anatase (around $85 \%$ ) as the main crystalline phase along with brookite. Average particle sizes, estimated from line-broadening according to the Scherrer equation, gave 5.4 and $12 \mathrm{~nm}$, for anatase and brookite phases, respectively. The morphology of the particles was examined by transmission electron microscopy and revealed highly agglomerated nanocrystals of 6-8 $\mathrm{nm}$ in length (Fig. 2).

Fig. 3 shows the nitrogen adsorption-desorption isotherms and the corresponding pore size distribution curve (inset) for desorbed sample $2\left(200{ }^{\circ} \mathrm{C} / 6 \mathrm{~h}\right)$. The BET surface area was 250 $\mathrm{m} \mathrm{g}^{-1}$ (243 $\mathrm{m} \mathrm{g}^{-1}$ for $\mathrm{TiO}_{2}$ obtained by the same procedure) and the total pore volume was $0.33 \mathrm{~cm}^{3} \mathrm{~g}^{1}$ (determined by BJH method). The isotherm, a type IV with a hysteresis of type $\mathrm{H} 2$, shows that $\mathbf{2}$ is a well-characterised ordered mesoporous system with interconnected particles, different from $\mathrm{TiO}_{2}$ (less 


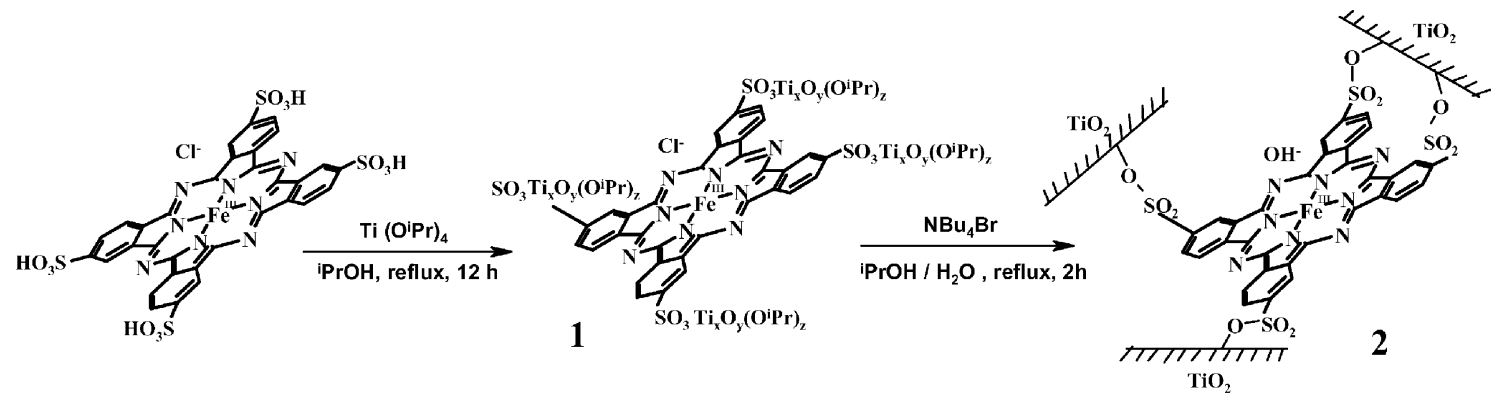

Fig. 1 Preparation of $\mathrm{FePcS}-\mathrm{TiO}_{2}$ (2).

rigid texture). This self-assembly process gave an average pore diameter with a narrow distribution of about $5 \mathrm{~nm}$, comparable with the size of the phthalocyanine ligand $(2 \times 2 \mathrm{~nm})$.

The catalytic activity of $\mathbf{2}$ has been determined in the TBHP oxidation of 2,3,6-trimethylphenol (TMP) into 2,3,6-trimethylquinone (TMQ), a precursor of vitamin E industrially obtained by $p$-sulfonation with $\mathrm{H}_{2} \mathrm{SO}_{4}$ followed by stoichiometric oxidation with $\mathrm{MnO}_{2}$. While only 20\% conversion and 1\% TMQ yield were obtained with $\mathrm{TiO}_{2}$ after $2 \mathrm{~h}, 2$ provided $96 \%$ conversion and $57 \%$ yield of TMQ under identical reaction conditions. ${ }^{9}$ Using $\mathrm{H}_{2} \mathrm{O}_{2}, 2$ was less active (44\% conversion) but high selectivity $(84 \%)$ was achieved. In the presence of $\mathrm{TiO}_{2}$, TMP conversion was only $15 \%$. It should be noted that conventional $\mathrm{FePcS}-\mathrm{SiO}_{2}$ catalysts were not active in oxidation of TMP using $\mathrm{H}_{2} \mathrm{O}_{2}$ as oxidant. ${ }^{3}$ These data show that combination of two catalytically active FePcS and Ti-based sites in one material could result in co-operative catalysis providing an improved catalyst.

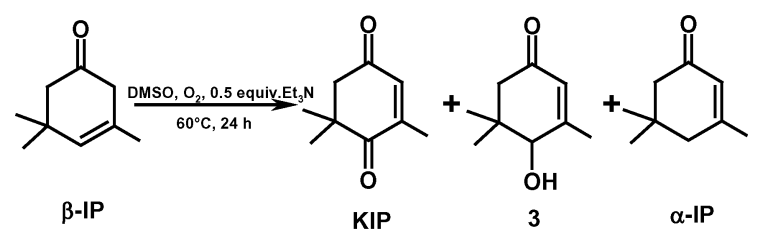

In order to confirm the superior catalytic properties of $\mathbf{2}$ we studied the aerobic oxidation of $\beta$-isophorone ( $\beta$-IP), an important intermediate for the preparation of flavors and fragrances fine chemicals. The transformation of $\beta$-IP to epoxide has been described. ${ }^{10}$ Several homogeneous ${ }^{11}$ and heterogeneous ${ }^{12}$ catalysts for the oxidation of $\beta$-IP to ketoisophorone (KIP) have been published. Homogeneous phthalocyanine and porphyrin complexes of different transition metals were used for aerobic $\beta$-IP oxidation in the presence of $\mathrm{Et}_{3} \mathrm{~N}$. ${ }^{13}$ With 1.3

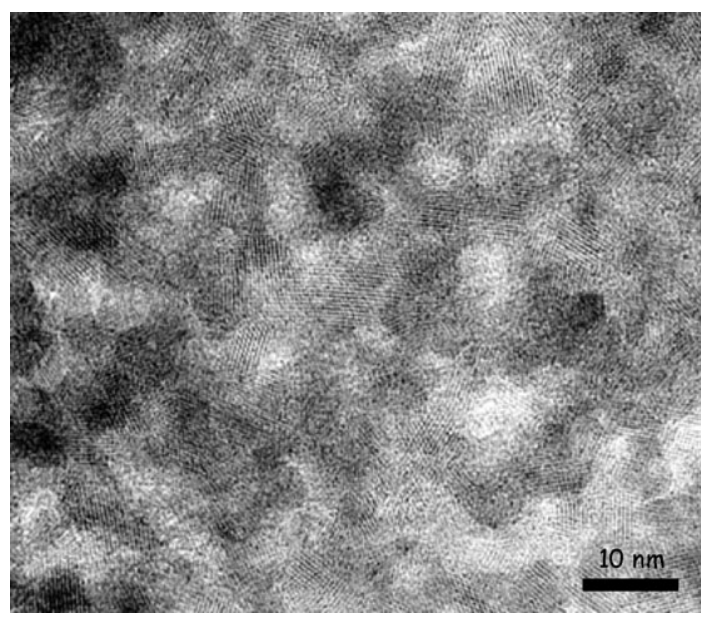

Fig. 2 TEM image of 2 obtained on a JEOL 2010 electron microscope. mol\% of FePc $55 \%$ yield of KIP was obtained. Manganese porphyrin complexes were the most efficient catalysts to provide $93 \%$ KIP yield. Recently, Murphy and Baiker reported an efficient homogeneous oxidation of $\beta$-IP in the presence of $\mathrm{Cu}$ (salen) (100\% conversion, $67 \%$ yield of KIP). ${ }^{11}$ However, only $52 \%$ conversion and less than $6 \%$ KIP yield was obtained in the best case with the $\mathrm{Cu}\left(\right.$ salen) catalyst supported on $\mathrm{SiO}_{2}$. This very low activity and poor selectivity in the heterogeneous oxidation were explained by the different reaction pathways imposed by the isolated immobilised catalytic sites. ${ }^{12 b}$ Additionally, metal(salen) complexes were not stable against leaching of the metal from the solid silica matrix.

We were delighted to observe that $\beta$-IP was successfully oxidised by $\mathrm{O}_{2}$ to give KIP, allylic alcohol 3 and $\alpha$-IP, the isomerisation product formed from the enolate intermediate. ${ }^{14}$ In the presence of $\mathrm{FePcS}-\mathrm{SiO}_{2} \beta$-IP was oxidised by dioxygen to afford $38 \%$ yield of KIP (Table 1). In the presence of $\mathrm{TiO}_{2}$ only $2 \%$ yield of KIP was obtained, $\alpha$-IP being the main product. FePcS supported on $\mathrm{TiO}_{2}$ performed much better than FePcS supported on $\mathrm{SiO}_{2}$ or $\mathrm{TiO}_{2}$ alone giving 57\% KIP yield. It is notable that the combined yield of KIP and 3 was $78 \%$ for $2\left(\mathrm{FePcS}-\mathrm{TiO}_{2}\right)$ compared to $45 \%$ for $\mathrm{FePcS}-\mathrm{SiO}_{2}$ suggesting cooperativity of the two catalytic sites in the oxidation.

Taking into account the importance of recyclability of heterogeneous catalysts we studied the recycling of $\mathbf{2}$ and the possibility of metal leaching into solution at $1 \mathrm{mmol} \beta$-IP scale and $10 \mathrm{~mL}$ reaction mixture. After completing the first run the catalyst 2 was isolated by centrifugation, washed with $\mathrm{MeCN}$ $(2 \times 25 \mathrm{ml})$ and dried. On reuse, we observed a gradual decrease of catalytic activity, 77 and $64 \%$ conversion in runs 2 and 3, respectively (Table 1). The yield of KIP was also lower, $33 \%$ (run 2) and $27 \%$ (run 3 ). In order to determine possible Fe leaching in solution we isolated the solution after run 1 by filtration $(0.45 \mu \mathrm{m}$ filter $)$. The residual $\mathrm{Fe}$ content in this solution of $7 \mathrm{ppm}$ indicated that $9.9 \%$ of fixed $\mathrm{FePcS}$ was dissolved in the reaction mixture. However, taking into account the very small particle size of $\mathbf{2}$ we can not exclude the

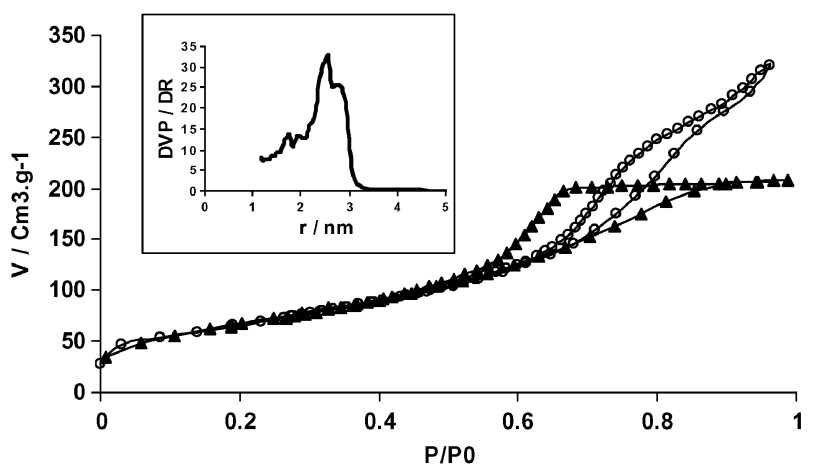

Fig. 3 Nitrogen adsorption-desorption isotherms of samples $2(\boldsymbol{A})$ and $\mathrm{TiO}_{2}(\mathrm{O})$ and pore size distribution $v$ s. radius (inset). 
Table 1 Heterogeneous oxidation of $\beta$-IP $\mathrm{IP}^{a}$

\begin{tabular}{llccc}
\hline Catalyst & Conversion (\%) & KIP & Yield $^{b}(\%$ 3) & $\alpha$-IP \\
\hline $\mathbf{2}\left(\mathrm{FePcS}-\mathrm{TiO}_{2}\right)$ & 99 & 57 & 21 & 10 \\
$\mathbf{2}($ run 2) & 77 & 33 & 9 & 16 \\
$\mathbf{2}($ run 3) & 64 & 27 & 6 & 20 \\
$\mathbf{2}^{c}$ & 68 & 29 & 7 & 15 \\
$\mathbf{2}^{d}$ & 77 & 40 & 9 & 17 \\
$\mathrm{TiO}_{2}$ & 97 & 2 & 4 & 46 \\
$\mathrm{FePcS}_{-} \mathrm{SiO}_{2}$ & 92 & 38 & 7 & 22
\end{tabular}

${ }^{a}$ Reaction conditions: substrate $(0.1 \mathrm{mmol})$, catalyst $(15 \mathrm{mg}, 1 \mathrm{~mol} \%$ to substrate), triethylamine $(0.05 \mathrm{mmol})$, dimethyl sulfoxide $(1 \mathrm{~mL})$ $60{ }^{\circ} \mathrm{C}, \mathrm{O}_{2}$ atmosphere, $24 \mathrm{~h} .{ }^{b}$ Determined by GC. ${ }^{c}$ After $5 \mathrm{~h}$ of reaction, the solid catalyst was separated by filtration and the solution was allowed to react for $19 \mathrm{~h}$ (total reaction time $=24 \mathrm{~h}$ ). ${ }^{d}$ Subsequent oxidation run with the catalyst separated after $5 \mathrm{~h}$ of reaction.

presence of the smallest catalyst particles in the solution after filtration. In a separate experiment the catalyst was filtered after $5 \mathrm{~h}$ of reaction when the conversion was $48 \%$, KIP yield was $25 \%$ and $\alpha$-IP yield was $4 \%$. The solution was allowed to react further. After $19 \mathrm{~h}(24 \mathrm{~h}$ total reaction time) the conversion was $68 \%(+20 \%$ as compared with $5 \mathrm{~h}$ reaction time). The yield of KIP increased from 25 to only $29 \%(+4 \%)$ while the yield of $\alpha$-IP increased from $4 \%$ to $15 \%(+11 \%)$. Comparison of these data with those obtained from standard oxidation (Table 1, run 1) shows significant decreases of catalytic activity $(-31 \%)$ and KIP yield $(-28 \%)$ after removal of the supported catalyst, and $5 \%$ increase in $\alpha$-IP yield. The recycled catalyst was used for the subsequent cycle. Similarly to run 2, in this second oxidation the conversion was $77 \%$, the yield of KIP was $40 \%$ and the yield of $\alpha$-IP was $17 \%$ thus demonstrating a good reproducibility of recycling. These results suggest that the oxidation of $\beta$-IP to KIP occurs mainly at the supported catalyst and the reaction of isomerisation of $\beta$-IP to $\alpha$-IP occurs in solution containing triethylamine base. The FePcS$\mathrm{TiO}_{2}$ catalyst recovered after three successive oxidations exhibited practically the same diffuse reflectance (DR) UV-Vis spectrum as that of the initial supported catalyst indicating no significant degradation (Fig. 4).

Although further work is still required to understand the mechanism of synergistic action, to optimise this novel oxidation catalyst in terms of selectivity and scope and to improve its recyclability, the KIP yield already obtained with $\mathbf{2}$ provides the basis for a heterogeneous oxidation of such an important substrate as $\beta$-isophorone.

In summary, iron(III) phthalocyanine was successfully covalently grafted onto crystalline $\mathrm{TiO}_{2}$ nanoparticles by a simple one-pot sol-gel process. This method avoids preliminary modifications of either the support or the metal complex that are usually necessary in conventional procedures. Tetrasulfophthalocyanine acts as a bridging ligand and controls the

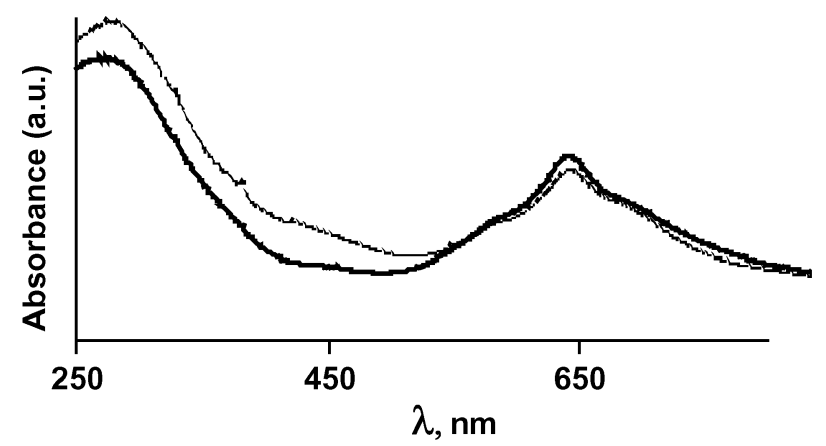

Fig. 4 DR UV-Vis spectra of initial FePcS-TiO 2 (bold line) and after 3 oxidations (light line). molecular self-assembly hydrolytic process which results in a new hybrid material with well-ordered mesoporous structure and high surface area. This catalyst containing two different catalytic sites exhibited promising results in heterogeneous aerobic oxidation of cyclic olefins exemplified by $\beta$-isophorone.

\section{Experimental}

All manipulations were performed under dry argon using Schlenk tube techniques. $\mathrm{Ti}\left(\mathrm{OPr}^{\mathrm{i}}\right)_{4}$ was purchased from Aldrich. Solvents were purified by standard methods and stored over molecular sieves. FT-IR spectra were recorded as Nujol mulls on a Perkin-Elmer Paragon 500 FT-IR spectrometer. UV-Visible spectra were carried out on an UNICAM UV2100 spectrometer. The DR UV-Vis spectra were recorded on a Lambda 35 Perkin-Elmer spectrophotometer. BET measurements were performed on a Micromeritics ASAP 2010. Powder X-Ray diffraction data were obtained with a Siemens D 5000 diffractometer using the $\mathrm{CuK} \alpha$ radiation. XPS experiments were performed with an Escalab 200R (VG Scientific) spectrometer using the monochromated $\mathrm{AlK} \alpha$ radiation as excitation source. TEM images were collected on a JEOL 2010 microscope. Analytical data were determined by an inductively coupled plasma-mass spectrometry method.

\section{Materials synthesis}

Synthesis of anhydrous $\left[\mathrm{FePc}\left(\mathrm{SO}_{3} \mathrm{H}\right)_{4}\right] \mathrm{Cl}$. Sodium salt of $\mathrm{FePcS}$ (600 $\mathrm{mg}$ in $50 \mathrm{~mL}$ of water), prepared according to the modified Weber-Busch procedure, ${ }^{15}$ was converted to the tetrabutylammonium salt by the treatment with $5 \mathrm{~mL}$ of a $40 \%$ tetrabutylammonium hydroxide aqueous solution followed by the extraction with $\mathrm{CH}_{2} \mathrm{Cl}_{2}(6 \times 50 \mathrm{ml})$. The organic phase was dried and the obtained material was dissolved in $200 \mathrm{~mL}$ of acetonitrile. $37 \% \mathrm{HCl}(2 \mathrm{~mL}$, about 6-fold excess with respect to the sulfonate group) was added dropwise under stirring. The precipitate of $\left[\mathrm{FePc}\left(\mathrm{SO}_{3} \mathrm{H}\right)_{4}\right] \mathrm{Cl}$ was isolated by centrifugation and dried at $60{ }^{\circ} \mathrm{C}$ for $24 \mathrm{~h}$ in vacuo. $\left[\mathrm{FePc}\left(\mathrm{SO}_{3} \mathrm{H}\right)_{4}\right] \mathrm{Cl}$ was further dried by the azeotropic distillation of ethanol. Finally, the product was dried in vacuo at $60{ }^{\circ} \mathrm{C}$ for $24 \mathrm{~h}(435 \mathrm{mg}, 91 \%$ yield). FT-IR (Nujol, $\mathrm{cm}^{-1}$ ): $3423 \mathrm{br}, 3173[\nu \mathrm{O}-\mathrm{H}]$; 1771w, $1715 \mathrm{~m}, 1604 \mathrm{~m}, 1504 \mathrm{~m}[\nu(\mathrm{C}=\mathrm{N}, \mathrm{C}=\mathrm{C})]$; $1330 \mathrm{w}, 1306 \mathrm{w}$; $1258 \mathrm{w}, 1227 \mathrm{~m}, 1182 \mathrm{~s}, 1169 \mathrm{~s}, 1147 \mathrm{~s}, 1107 \mathrm{~s}, 1089 \mathrm{~s}, 1052 \mathrm{~m}$, 1027s $\left[\nu\left(\mathrm{SO}_{3}\right)\right] ; 963 \mathrm{~m}, 929 \mathrm{~m}, 844 \mathrm{w}, 762 \mathrm{w}, 748 \mathrm{~m}, 700 \mathrm{~s}, 677 \mathrm{w}$, $650 \mathrm{~s}, 630 \mathrm{~s}, 598 \mathrm{~m}, 591 \mathrm{~m}, 566 \mathrm{~m}, 543 \mathrm{w}$.

Synthesis of 1. In a typical preparation, $0.74 \mathrm{~g}(2.6 \mathrm{mmol})$ of $\mathrm{Ti}\left(\mathrm{OPr}^{\mathrm{i}}\right)_{4}$ and $0.194 \mathrm{~g}(0.21 \mathrm{mmol})$ of $\left[\mathrm{FePc}\left(\mathrm{SO}_{3} \mathrm{H}\right)_{4}\right] \mathrm{Cl}$ were refluxed in 2-propanol for $12 \mathrm{~h}$. After filtration, the resultant dark green solution was concentrated under vacuum. Cooling it down to $-4{ }^{\circ} \mathrm{C}$ resulted in a dark blue-green crystalline material $1(0.85 \mathrm{~g}, 60 \% / \mathrm{Fe})$. Anal. Found: Fe, 0.45; Ti, $15.15 \%$. FT-IR (Nujol, $\mathrm{cm}^{-1}$ ): 1775w, 1772m, 1685w, 1606m, $1581 \mathrm{w}, 1512 \mathrm{~m}, 1463 \mathrm{w} \quad[\nu(\mathrm{C}=\mathrm{N}, \quad \mathrm{C}=\mathrm{C})] ; 1336 \mathrm{w}, 1325 \mathrm{~m}$, $1308 \mathrm{w} ; 1263 \mathrm{w}, 1227 \mathrm{w}, 1186 \mathrm{w}, 1161 \mathrm{w}, 1146 \mathrm{~m}\left[\nu\left(\mathrm{SO}_{3}\right)\right] ; 702 \mathrm{w}$, 696w, 648m, 632m, 601w, 595w, 567w, 524w, 508w, 468w $[\nu(\mathrm{M}-\mathrm{O}, \mathrm{M}-\mathrm{N})]$.

Synthesis of 2. In a typical hydrolysis process, $1 \mathrm{~g}$ of $\mathbf{1}(83.1$ $\mu \mathrm{mol})$ in $5 \mathrm{~mL}$ of 2-propanol was added dropwise to $25 \mathrm{~mL}$ of a $\mathrm{N}\left({ }^{\mathrm{n}} \mathrm{Bu}\right)_{4} \mathrm{Br}(0.4 \mathrm{~g}, 1.24 \mathrm{mmol})$ aqueous solution under vigorous stirring at boiling temperature. The mixture was heated under reflux for $2 \mathrm{~h}$ and was centrifuged to give a dark blue-green solid. The as-prepared precipitate (denoted 2) was washed several times with deionised water, until the solution was colorless, and ethanol $(25 \mathrm{~mL})$ and was dried at $70{ }^{\circ} \mathrm{C}$ overnight. Anal. Found: Fe, 1.20\%. FT-IR $\left(\mathrm{KBr}, \mathrm{cm}^{-1}\right)$ : $3342 \mathrm{br}$ $[\nu \mathrm{O}-\mathrm{H}] ; 1722 \mathrm{~m}, 1617 \mathrm{~s}, 1539 \mathrm{~m}, 1481 \mathrm{w}, 1401 \mathrm{~m} \quad[\nu(\mathrm{C}=\mathrm{N}$, 
$\mathrm{C}=\mathrm{C})]$; 1254w, 1218w, 1187m, 1141w, 1101w, 1072w, 1032m $\left[\nu\left(\mathrm{SO}_{3}\right)\right] ; 721 \mathrm{~s}, 553 \mathrm{vs}, 478 \mathrm{vs}[\nu(\mathrm{M}-\mathrm{O}, \mathrm{M}-\mathrm{N})]$.

\section{Catalytic tests}

The reaction products were identified and quantified by GCMS (Hewlett-Packard 5973/6890 system; electron impact ionization at $70 \mathrm{eV}$, He carrier gas, $30 \mathrm{~m} \times 0.25 \mathrm{~mm}$ cross-linked $5 \%$ PH ME siloxane $(0.25 \mu \mathrm{m}$ coating $)$ capillary column, HP5MS) and GC (Agilent 4890D system, $\mathrm{N}_{2}$ carrier gas, $15 \mathrm{~m} \times$ $0.25 \mathrm{~mm}$ crosslinked 5\% PHME siloxane $(0.25 \mu \mathrm{m}$ coating $)$ capillary column, HP-5MS) methods.

Typical procedure for the oxidation of TMP. $2(8 \mathrm{mg}, 2$ mol\%) was added to a solution of TMP $(80 \mu \mathrm{mol})$ in $1,2-$ dichloroethane (DCE, $4 \mathrm{~mL}$ ), then four $15.8 \mu \mathrm{L}$ portions of a 3.8 M TBHP in DCE were added to the mixture at reaction times of $0,0.5,1,1.5 \mathrm{~h}$ (total oxidant amount: $240 \mu \mathrm{mol})$. The reaction was carried out at $30{ }^{\circ} \mathrm{C}$ for $2 \mathrm{~h}$. The products were identified by GC-MS and quantified by GC using authentic samples.

Typical procedure for the oxidation of $\boldsymbol{\beta}$-IP. Catalyst (1 mol\%) was added to a solution of $\beta$-IP $(0.1 \mathrm{mmol})$ in dimethyl sulfoxide $(1 \mathrm{ml})$ containing $0.05 \mathrm{mmol}$ of triethylamine. The reaction was performed at $60{ }^{\circ} \mathrm{C}$ under oxygen atmosphere $(2$ bar) for $24 \mathrm{~h}$. The products were identified by GC-MS and quantified by GC using authentic samples. Recycling experiments were carried out with $1 \mathrm{mmol} \beta$-IP keeping the same reagent ratio.

\section{Acknowledgements}

The authors thanks Mr W. Desquesnes for his help in interpretation of nitrogen adsorption-desorption isotherms.

\section{References}

1 G. Goutailler, C. Guillard, S. Daniele and L. G. Hubert-Pfalzgraf, J. Mater. Chem., 2003, 13, 342, and references therein.

2 C. Pérollier and A. B. Sorokin, Chem. Commun., 2002, 1548.

3 (a) A. B. Sorokin and A. Tuel, New J. Chem., 1999, 23, 473; (b) A.

B. Sorokin, S. Mangematin and C. Pergrale, J. Mol. Catal. A: Chem., 2002, 182-183, 267; (c) S. V. Barkanova and O. L. Kaliya, J. Porphyrins Phthalocyanines, 1999, 3, 180.

4 (a) A. B. Sorokin, J.-L. Séris and B. Meunier, Science, 1995, 268, 1163; (b) A. B. Sorokin and B. Meunier, Chem. Eur. J., 1996, 2, 1308; (c) B. Meunier and A. B. Sorokin, Acc. Chem. Res., 1997, 30, 470; (d) X. Tao, W. Ma, J. Li, Y. Huang, J. Zhao and J. C. Yu, Chem. Commun., 2003, 80; (e) M. Bressan, N. d'Alessandro, L. Liberatore and A. Morvillo, Coord. Chem. Rev., 1999, 185-186, 385.

5 A. P. Hong, D. W. Bahnemann and M. R. Hoffmann, J. Phys. Chem., 1987, 91, 2109.

6 G. Mele, G. Ciccarella, G. Vasapollo, E. Garcia-Lopez, L. Palmisano and M. Schiavello, Appl. Catal. B, 2002, 38, 309.

7 A. Gosh, J. Fitzgerald, P. G. Gassman and J. Almlöf, Inorg. Chem., 1994, 33, 6057.

8 H. Zhan, W. Chen and M. Wang, Mater. Lett., 2003, 57, 1108.

9 For TMP oxidation on Ti-based catalysts, see: O. A. Kholdeeva, N. N. Trukhan, M. P. Vanina, V. N. Romannikov, V. N. Parmon, J. Mrowiec-Bialon and A. B. Jarzebski, Catal. Today, 2002, 75, 203, and references therein.

10 (a) R. Hutter, T. Mallat and A. Baiker, J. Catal., 1995, 157, 665, and references therein; (b) T. Honma, M. Nakajo, T. Mizugaki, K. Ebitani and K. Kaneda, Tetrahedron Lett., 2002, 43, 6229.

11 E. F. Murphy, M. Schneider, T. Malat and A. Baiker, Synthesis, 2001, 547.

12 (a) E. F. Murphy, T. Malat and A. Baiker, Catal. Today, 2000, 57, 115; (b) E. F. Murphy and A. Baiker, J. Mol. Catal. A: Chem., $2002,179,233$, and references therein.

13 N. Ito, T. Etoh, H. Hagiwara and M. Kato, Synthesis, 1997, 153.

14 M. Constantini, A. Dromard, M. Jouffret, B. Brossard and J. Varagnat, J. Mol. Catal., 1980, 7, 89.

15 (a) J. H. Weber and D. H. Busch, Inorg. Chem., 1965, 4, 469; (b) A. Hadasch, A. B. Sorokin, A. Rabion and B. Meunier, New J. Chem., 1998, 22, 45. 